\title{
Reflections on the teaching of applied optics
}

\author{
Robin Smith
}

Robin W. Smith, "Reflections on the teaching of applied optics," Proc. SPIE 1603, Education in Optics, (1 March 1992); doi: 10.1117/12.57851

SPIE. Event: Education in Optics, 1991, Leningrad, Russian Federation 


\title{
Reflections on the teaching of applied optics
}

\author{
Robin Smith \\ Applied Optics Group, The Blackett Laboratory, \\ Imperial College of Science Technology and Medicine, London SW7 2BZ, U.K.
}

\begin{abstract}
ABSTRAC.T
In this paper some personal views based on over 20 years experience of teaching optics at undergraduate level and applied optics at postgraduate level are presented, distinctions are drawn between undergraduate optics and applied optics.
\end{abstract}

\section{OPTICS AND APPLIED OPTICS}

Historically most school physics courses have been broken down into major topics such as - heat, properties of matter, sound, electricity and magnetism and so on - with optics studied under the general heading "light". In school physics laboratories experiments using ray boxes, pins, lenses, and mirrors are of obvious attraction to the young. Later, more advanced level experiments involving diffraction and interference are used to introduce the wave nature of light, and experiments using lasers for a variety of purposes including holography are common in most senior school and university undergraduate laboratories.

At university level the physics syllabus is expanded to include many new subject areas such as relativity, quantum mechanics, nuclear physics and statistical mechanics and so on, and usually most undergraduate syllabuses only contain (i) a short first year course on elementary optics and (ii) an optional final year course on what is often called modern optics. Thus for some students, their experience in optics is limited to a few lectures on geometrical optics and usually a large number on physical optics covering diffraction and interference. In addition, since the advent of readily available $\mathrm{HeNe}$ lasers, nearly all students do some optical experiments during their laboratory work.

Students who take the optional modern optics courses hear about lasers and their applications (including holography), diffraction and image formation (Fourier optics) and perhaps opto-electronics, elementary nonlinear optics and fibre-optics.

It must be remembered that optics appears indirectly in a large number of other courses, for example the treatment of Fresnel reflection and transmission coefficients in electromagnetism and in atomic physics where spectroscopic instrumentation is fundamental to the observations on which most of subject is built.

Because of the way in which they are presented the optics topics mentioned above do not , in my opinion constitute what I would call Applied Optics.

What is Applied Optics?

Who is it for?

How should it be taught?

In what follows I give my personal reflections on the teaching of applied optics presented in the form of answers to a series of questions. I trust that these reflections do not appear too much as random scattering and retain some of the clarity of pure specular reflection! 


\section{WHAT IS APPLIED OPTICS ?}

I think the word Applied clearly indicates that this is a subject concerned with "doing optics" and not just with observing or noting optical phenomena, nor even using optics as the means of demonstrating basic physical principles. However this does not imply that Applied Optics is a purely technological and practical subject excluding deep theoretical studies and scholarship.

Perhaps a suitable definition might be that Applied Optics is concerned with all aspects of optical measurement. This is in fact a very broad definition, because, as well as including the theoretical and practical details of the light source, the optical components, the detection system etc. it also covers the physics of the phenomena on which the measurements are based.

Probably the most important part of any training in Applied Optics is the study of the fundamental limitations of any optical system. The student must learn to recognise these basic physical and technological limitations and gain experience in designing and operating systems at these limits. It takes a long time to gain a working knowledge of these limitations. It certainly cannot just be learnt from books!

This is a very broad definition and very few workers in Applied Optics have deep knowledge of the whole field, most are specialists in one or more particular areas. A good example is the lens designer who ideally, should not just follow the narrow path of lens design but, through training in applied optics, be able to appreciate the details of the application of the lens he is designing and be able to discuss the work beyond the specification he has been given.

Applied Optics is therefore not just part of standard undergraduate physics. Perhaps, as it involves design skills, it is better described as part of applied or engineering physics and it is therefore not surprising that in many centres it is included in departments of electrical engineering.

\section{WHO IS IT FOR ?}

People with training in Applied Optics rarely find employment which is restricted entirely to applied optics, (an exception might be some lens designers). A university course in Applied Optics should start at a level suitable to those whose previous training might have been in physics, electrical engineering, mechanical engineering, mathematics and technology.

In designing the course it should be remembered that in later employment, most applied optics graduates will soon need some of the skills of project management. Unfortunately there is usually little time available for such topics in the course. However it is important that the students should be given some idea, however little, of the reality of how applied optics is actually done in industry.

\section{AT WHAT LEVELS SHOULD IT BE TAUGHT ?}

In the UK Applied Optics is usually a postgraduate subject and this leads to the contradiction that, in order to gain fundamental understanding, it is necessary for the students to go back and start at a very basic level; often in most topics at a level which might be considered, in the context of a university degree, as rather too elementary!

However Applied Optics involves skills and skills can only be acquired, (note not learned), via experience and considerable attention must be paid to the simplest of activities. A good example is the skill needed in laying out the paraxial design of an optical system. Afterwards it is all very obvious. But faced with a blank sheet of paper and only the knowledge that

$$
\frac{1}{l^{\prime}}-\frac{1}{l}=\frac{1}{f}
$$

where does one start?

Until completed anamorphic system layouts are certainly not very obvious: how marvellous is the power of hindsight! 
I think that the intellectual effort required for acquiring skills differs greatly from that needed to follow undergraduate courses for the immediate purpose of passing an examination. One must never be afraid of appearing silly by asking the simplest of questions, most of us, as teachers, will have, I am sure experienced great difficulties in answering such questions and learnt from the process, and if the truth be known, still wish to ask such questions ourselves. We often come across nonsense written in papers by workers who are clearly out of their depth and who have not spent enough time really getting to understand their subject.

\section{CAN IT BE TAUGHT OR IS IT A SKILL ?}

In principle a student can attend a course of lectures, learn that course material, sit and pass an examination and leave with a nominal qualification in Applied Optics without acquiring any skills in the subject. Such a minimum qualification has little value in the market place because the student will only have the experience of answering the somewhat artificial questions set by the examiners.

What the students need is to be put in situations where they will, one hopes, start to ask their own questions and in answering them acquire a real working knowledge which they will retain long after the course is over and be able to apply to a wide range of practical problems. Applied Optics might be considered essentially as a set of skills linked by a broad base of principles. Of course in addition the students need to equip themselves with a good general knowledge of facts and data about materials and devices.

\section{WHO BENEFITS FROM IT?}

Clearly, as a vocational training, it is of direct applicability by students going into industrial design and development, but what about university research?

In the UK postgraduate students have been awarded financial support to follow courses leading in one year to an $\mathrm{MSc}$ or in three years to a $\mathrm{PhD}$. At Imperial College the PhD students are usually required by their supervisors to attend many of the Applied Optics MSc lectures. (In fact students from other institutions and some from industry also attend). This has meant that, although the PhD candidates have seen some of the MSc lecture course material, they missed out on most of the skill-aquiring activities of the course and despite leaving with the higher qualification have very sketchy notions of what the subject is all about.

It is very pleasing to see at last that the principal funding agency in the UK, the SERC, has recently allowed students after they have completed an MSc, three further years funding for a PhD. The MSc although designed for industrial training does provide an excellent foundation for research.

\section{DOES IT KEEP UP TO DATE ?}

Keeping up to date in Applied Optics perhaps means that one is aware of the latest developments of devices and materials. Should courses therefore be continuously changing, older material being removed so that details of the latest devices and techniques can be included?

When this is done great care must be taken to ensure that the fundamental aspects of the course are retained and novelty must not dominate the choice of course content. It is most important that the course should not just be a catalogue of devices but should be built around basic themes with the newer devices and techniques used as examples.

\section{WHAT SHOULD THE STUDENTS READ?}

This is part of keeping up to date. Clearly the students should be familiar with the important archival journals in optics. In addition useful information about basic Applied Optics is contained in suppliers' and manufacturers' catalogues and in the monthly trade publications. The latter often provide up to date review articles on topical matters, new devices and indicate the trends in the market place; very important in such areas as - developments in diode lasers, opto-electronic devices, detectors and fibre optics. 


\section{WHAT COURSES SHOULD IT CONTAIN?}

Here I present a summary of the lecture courses included in the Applied Optics MSc at Imperial College, London.

This course has existed in one form or another for about 50 years. In the early days it was mainly concerned with lens and optical instrument design but over the years it has been extended to include lasers, non-linear optics, quantum optics and integrated optics.

The course is split into core and option lecture courses as follows:-

\section{Core Courses}

Geometrical Optics and Aberration Theory

Diffraction and Image Formation

Lens Design

Testing Optical Systems and Interferometry

Thin Films

Quantum Electronics

Introductory Non-Linear Optics

Optical Hardware

Optics In Industry

\section{Option Courses}

(25)

(10)

Partial Coherence

Integrated Optics

Electron Optics
Advanced Lens Design

Holography and Optical Image Processing

Detection and Noise

Advanced Non-Linear Optics

Optical Communications

Physiological Optics

The figures in brackets roughly indicate the number of lectures. This distribution of lectures between the various subject areas has developed over the years and changes from time to time to accommodate important developments in the subject and the experience of the lecturing staff.

The students attend all the core courses and attend at least 5 of the option courses. Usually, out of interest, they attend more option courses than is absolutely necessary for the purpose of examination preparation.

Of the core courses those in Geometrical Optics and Aberration Theory, Diffraction and Image Formation, Lens Design, Testing Optical Systems and Interferometry, Thin Films, Quantum Electronics and Optical Hardware probably make up the minimum content for an Applied Optics course. The students need to understand the basic material in these courses in order to appreciate fully the practical laboratory work and also the work that follows in the option courses.

The Optical Hardware course contains a few lectures on each of many important applied optics topics. The emphasis is on practical aspects of materials and devices and the course contains lectures on, for example, optical glasses and other optical materials, spectrometer mountings, basic crystal optics and polarisation devices.

\section{WHAT TYPES OF PRACTICAL WORK ?}

One of the major problems one has to face in trying to teach a subject like Applied Optics by means of lectures is that for much of the time most students have very little first hand experience of the topic under discussion. An obvious example of this is the introduction of tilt-fringes in a wavefront measuring interferometer. The theory says something like "..... adjusting the plane mirror introduces a tilt $W(x, y)=a x+b y \ldots .$. " Until you have done this yourself and seen the resulting effect on the wavefront interferogram displayed in an interferometer the whole concept has very little mieaning.

To try to help the students and to bring some reality into the lectures at the beginning of their course we have introduced an intensive set of simple experiments each designed to demonstrate one or two basic principles or concepts in Applied Optics. An experienced person would take less than one hour to complete each of these experiments but we allow the students 3 hours to do so. This gives them time to discuss their observations and problems with the staff demonstrators and each other. By this means we have been able to introduce the students 
to about 25 different aspects of Applied Optics during the first four weeks of their course. This greatly helps them to understand and appreciate the significance of the new material they meet in their lectures.

After completing this set of demonstration experiments the students working in pairs choose three standard experiments each of which takes about two weeks to complete. Many of these experiments are concerned with optical measurement, optical testing and interferometry.

We have tried to introduce laser and non-linear optics experiments but have found that although we have had a lot of fun designing and setting them up the nature of most of these experiments, (especially safety), means that the students, more often than not, are just left with making observations and recording results, without being involved in the design of the experiment.

An exception is a demountable HeNe laser consisting of mirrors mounted on standard optical bench fittings and a wide bore plasma tube with Brewster angle windows (such wide bore tubes are not easy to find these days). The students are able to adjust the laser cavity to study cavity stability criteria, longitudinal modes using a large spacing Fabry-Perot interferometer and transverse mode patterns; such experiments are not possible with the standard commercially available low power HeNe lasers.

About half way through the year the students, again working in pairs, are allocated an optical system design problem. In a period of six weeks they must produce a working prototype piece of optical equipment. To save time we give them access to kits which include most the optical and mechanical components they might want to use. Their task is firstly to establish what techniques might be used to solve their task, secondly by means of calculation and rough experiments to select the one they consider to be the most feasible (justifying this to their supervisor) and thirdly to complete their design and to construct and test their prototype instrument. They have to reach the stage of generating on an oscilloscope an appropriate output signal but do not have to complete the signal processing electronics. Examples of such projects include bar code readers, position measuring interferometers, measuring the shape of small objects and laser Doppler velocimetry.

By the end of the six weeks the students must produce a report detailing and justifying their choice of technique for solving the problem, assessing the success of the prototype, identifying its shortcomings, suggesting how it might be improved, giving a component source list with prices and an estimate of the cost of their own time spent on the project.

We find that such problems really focus the student's thought! Almost as soon as they start they have to ask themselves questions about such topics as resolution, depth of focus, signal strengths and problems of noise and interference; all topics included somewhere in the lecture courses but now brought alive by the student's need to apply them to real situations.

The students also spend quite a lot of time on optical design. This, introduced by means of lectures, is mainly taught through sets of design assignments. These start at a necessary elementary level involving the use of calculators, pencil and paper paraxial layout drawing, writing simple ray tracing programmes, eventually leading to access to standard commercial software. The latter are available to the students only after they have gained sufficient experience to understand what they are really trying to do when they attempt to use the sophisticated software; here the golden rule is better late than too early!

\section{HOW EXAMINED?}

Examinations, needed to satisfy university regulations, do serve some other useful purposes, for example they provide students with a scale against which to measure their own progress and sets of practice problems . Unfortunately it is almost impossible to set realistic Applied Optics problems that can be solved under examination conditions. It is therefore particularly important that the students be assessed in the manner they carry out their practical work and design assignments.

However I personally must admit that I find assessment and teaching often do not mix, as I am often only able 
to give students the guidance they need once they have already admitted or demonstrated lack of understanding, which in assessment terms could lead to a low grade.

\section{MAJOR PROJECT WORK}

After our students have completed all the laboratory, examination work, their optical system design projects and their lens design assignments, they undertake a full time three month summer project. This can be theoretical, experimental, computational, a critical literature survey, or a mixture. Many projects originate from the students themselves, others from industry allowing the students to spend most of their time with the company and others from university research groups in London or elsewhere. Recently we have established links with several European Universities through the EEC ERASMUS student exchange scheme and whilst completing their projects abroad the students benefit by becoming proficient in a foreign language.

In many ways these long projects represent the culmination of each student's training, a realistic problem with a reasonable time scale, none of the artificial pressures of examinations, the student able to approach the problem and organise his work in his own way, the opportunity to establish a modus operandi for the future. For these reasons we give the project a heavy weighting in our final grade assessment.

\section{ARE WRITTEN LABORATORY REPORTS NECESSARY?}

Yes. The students should be asked to produce concise written reports on all types of laboratory and project work. Often students in an misguided attempt to impress us produce reports which are far too discursive and not to the point, our way of dealing with this is to apply a guillotine cutting off everything after ten sides of text (including graphs and diagrams), this tends to concentrate the student's mind enormously.

A new problem is the word-processor. Why is there a difficulty here? Great effort can go into generating a beautifully presented document with very poor quality science content. Students easily find time to compete with each other to produce the most sophisticated presentation. The tired marker needs to watch the content not the type! We are careful to allocate only a small fraction of the marks to presentation (word-processing), most are awarded for clarity, content and organisation.

\section{LINKS TO INDUSTRY?}

Without strong links to industry a course in Applied Optics probably has little value. Industrial links ensure that the course content is relevant and up to date. Project work in industry has already been mentioned. The "Optics in Industry" lecture course is given by practising experts in Applied Optics from industry.

Like many universities we operate an Industrial Associate Scheme with members enjoying a special relationship with the college and regularly visiting us.

For about 60 years there has been in existence an Optical Advisory Committee whose members, representing most of the branches of the optics industry, advise us particularly with reference to training in Applied Optics. This committee provides a strong link with current industrial practice.

Although industrial managers often look to the universities for help they do not in general view universtities as sources of cheap consultancy, instead they expect and rely on them to be places where valuable independent scholarship is undertaken.

\section{CONTINUING EDUCATION ?}

There is a need for workers in industry to have access to training to enable them to enter new areas of work or to update their existing knowledge in a subject. With the current very strong interest in all subjects optical it is not surprising that we have been able to run successful courses in Applied Optics (two weeks), Nonlinear Optics (four days) and Lasers and their Applications (one week). These courses have generally taken the form of intensive lectures with detailed printed notes and laboratory visits and demonstrations. Such courses as well as meeting the needs of industry greatly strengthen the industrial links mentioned above. 
We recently ran a new course entitled "A Practical Introduction to Optical Design" under a completely different format. Each lecture of about 45 minutes was followed by about 90 minutes of "hands on" practical work. The attendees put pencil to paper to solve simple optical layout problems. They did a lot of drawing and eventually got as far as the paraxial laying out for a zoom system. We discovered that even people with considerable experience in optics needed time to understand material which at first glance may seem somewhat elementary. Extra time spent on basic material is never wasted.

\section{WHAT DOES HISTORY TELL US ?}

The simple answer is that nothing changes, the problems encountered in teaching Applied Optics in the 1990's are almost the same as those seen over 50 years ago when such teaching was first established at Imperial College.

I am grateful to my colleague Michael Barnett for bringing to my attention two letters which were published in the well known scientific journal Nature 1st March and 5th April, 1917 under the heading OPTICAL ABSTRACTS British Optical Science.

In the first Sir Joseph Larmor (Cambridge) opposes the view expressed in a report on the ".... national instruction in Technical Optics ....." that

"A further need, which is urgent, is the supply of standard text books dealing with those parts of Optics which at present are greatly neglected in this country; this includes practically the whole of Geometrical Optics and a large part of Technical Optics. In our opinion the quickest and most effective method of dealing with this requirement is by publishing translations of existing foreign books and abstracts of important papers on the subject".

In his letter Sir Joseph Larmor gives many examples of what he considers suitable texts.

In the second letter the industrialist James Weir French ( Barr and Stroud, Annisland, Glasgow) says that

".... not one of the books cited [by Sir Joseph Larmor ] deals with the method of optical computation actually adopted in the German workshops, and, indeed, there are extremely few books in Germany that do divulge the whole system. The British books are, no doubt, well adapted to enable students to pass examinations on general optics. For example, one of those cited has a large index, which includes the rainbow and the principal of relativity - questions, no doubt, that will find a place of honour in examination papers - but which does not refer to so vital a question as coma, to which alone a whole book should be devoted. There is great similarity in the present optical books. They all contain the same stereotyped material. Some deal with it in a non-mathematical way while others attack the propositions with heavy algebraic artillery. ......... A book devoted to, say, coma would have a very limited market whereas a book on optics if made sufficiently general can be made to appeal to students and school teachers and thus find a profitable market."

He quotes Silvanus P Thompson who complained that

"They call it optics, but it is really purely mathematical gymnastics applied to the optical problems of a hundred years ago." 
French concludes by exhorting mathematicians

“...... to enter the workshops first as learners not teachers. They may find the work laborious and monotonous from the point of view of the mathematician to whom a pretty solution is an object of some importance, but once they have experienced the pleasure of testing a system that accords with their calculations, they will never again be satisfied with the publication of untried formulae.

Clearly there are still messages here for us today.

\section{CONCLUSIONS - TRAVELLING LIGHT?}

Training in Applied Optics starts at about the age of 18 and goes on for most of us until retirement. The subject is one where experience is invaluable. Knowing about a topic means knowing how to practice it. Examination optics is just a means of getting started.

For each topic, there is a small number of important fundamental results which the applied optical worker needs to have at his finger tips, being able to apply them without the need to refer to textbooks. Of course he needs to have a thorough knowledge of what is in the text books but in addition he needs to have experienced the hard way what the results really mean. For example, in a course on diffraction, time spent plotting out by hand the distribution represented by the Airy's formulae $2 J_{1}(z) / z$ gives the student a real feeling for its form. Slick computer graphics are very valuable for presenting the results of ray tracing or detailed diffraction calculations but often isolate the student from the details of the subject.

We need to know about our subject, to experience these details, to carry with us the few important rules of thumb, that is - to travel light - ready to apply our knowledge to new situations using "back of the envelope calculations" and, perhaps most importantly of all, to encourage our students to do the same. 